\section{SCIENTIFIC AND INDUSTRIAL RESEARCH IN CANADA}

$\mathrm{T}$ HE twenty-fourth report of the National Research Council of Canada, 1940-41, includes the report of the president together with the reports of the directors of the various divisions (National Research Council of Canada. N.R.C. No. 1002 : Twenty-fourth Annual Report of the National Research Council of Canada, 1940-41. Pp. 28. Ottawa : National Research Council of Canada, 1941). The former well indicates the extent to which Canada's scientific resources are being mobilized in support of the war effort. In addition to its former role the Council is functioning as a research station for the three fighting services of the Department of National Defence and also for the Departments of Munitions and Supply, and the president's report refers to the way in which the National Research Council has been able to turn its peace-time programme almost overnight into one of service in war. For example, the Section on Metrology of the Division of Physics and Electrical Engineering has been expauded to provide the organization required for gauge testing, and to date there has been no delay whatever in dealing with this aspest of production. Similarly, the Radio Section was immediately turned to the development of secret radio communication and has made important contributions in the development of prototypes. The Section on Optics has dealt with the problem of optical glass and the manufacture of fire-control instruments, with the result that a well-equipped factory is already operating in Canada for the manufacture of optical glass and a wicle range of fire-control instruments. The Section on Radiology immediately turned its attention to industrial radiology and has organized laboratories and trained personnel for inspecting castings at the various industrial plants. The Section on Electrical Engineering has been engaged on the design and production of secret gear and equipment in connexion with naval protective devices, while the Section on Acoustics has been devoting its entire attention to acoustic problems for the navy and the Section on General Physics has done much valuable work on the design of instruments, ballistics, etc.

In the Division of Chemistry the laboratories devoted to textiles, leather and rubber have been engaged in testing war materials, developing substitutes and the preparation of specifications for war materials. Research on the manufacture of ethylen $\Theta$ glycol by direct oxidation has been continued with special reference to the stability of the catalysts. All research on methods of defence against chemical attack excepting training phases is directed by a special committee of which a member of the National Research Council is chairman and technical officers of the Department of National Defence and of the laboratories are members. This Committeo has organized and directed more than twenty research projects with the various university laboratories and in the Chemistry Division at Ottawa, as well as supervised the manufacture of all the gas masks in Canada. In the Mechanical Engineering Division the wind tunnels have been engaged on many miscellaneous projects in aerodynamics, and extensive co-operative investigations on lubricating oils and fuels have been undertaken. The model-testing basin is engaged in studies in connexion with boats and floats, and considerable fundamental work has been done by the
Division in the use of moulding plastic plywood construction. The Division of Biology and Agriculture has been concerned with many problems in the storage and transport of food which have become of prime importance owing to the difficulty of transport across the Atlantic. Medical research work has been carried out in close co-operation with technical officers of the Royal Canadian Army Medical Corps, and leading medical research men of Canada are working vigorously on important phases of war medicine. The National Research Council was also largely responsible for the organization of Research Enterprises Ltd., a Government-owned company formed for manufacturing certain special secret equipment from prototypes developed by the National Research Council. The report also refers to the intimate liaison established with the British Government and with research workers in Great Britain, and to the work of the Division of Physics and Electrical Engineering in selecting Canadian university men for special war service in the British Navy.

\section{NEW SPECTROGRAPHIC OBSERVA- TIONS OF PECULIAR STARS}

N

EW spectrographic observations of peculiar stars were discussed by O. Struve and P. Swings, of the MeDonald and Yerkes Observatories, at the Autumn Meeting of the U.S. National Academy of Sciences held during October 13-15. The MeDonald Observatory of the University of Texas (which is operated jointly by the University of Chicago and the University of Texas) is equipped with a powerful ultra-violet spectrograph. Two large crystal quartz prisms and lenses of quartz or of ultra-violet glass transmit stellar radiations to the limit imposed by the ozone bands in the atmosphere of the earth. During the past two and a half years this instrument has been used to record the spectra of a number of peculiar stars which had heretofore been investigated only in the ordinary photographic region of the spectrum. The ultra-violet region of the spectrum contains many important features : the limit of the Balmer series falls in the near ultra-violet where the lines crowd together and where photo-electric ioniza. tions produce a marked discontinuity in the distribution of the continuous spectrum.

Among the results obtained are several remarkable cases of changes in the spectra. Perhaps the most spectacular case is that of $\gamma$-Cassiopeiæ, which a few years ago was a normal emission line $B$ star, and which in 1940 had an almost pure absorption spectrum with very sharp lines, while at the present time the absorption lines are broad and very diffuse. We know that the emission lines come from a tenuous shell around the star. For some, as yet, obscure reason the shell began to change a few years ago. The authors suspect that it started closing in towards the star, producing an intermediate stage spectrum of sharp lines. Finally, early in 1940, the shell must have largely fallen into the reversing layer of the star.

The opposite series of events has taken place in several other stars ( $Z$ Andromeda, $A G$ Pegasi), where a new shell recently formed has expanded and has, in the case of $Z$ Andromedæ, progressed from the sharp-line absorption spectrum to an almost pure emission spectrum. 
These examples show that the processes of evolution in astronomy are not always imperceptibly slow. The outermost layers of stellar atmospheres are extremely unstable formations which often undergo marked changes in a few weeks or even days. Apparently these formations are supported by a delicate balance of three forces: gravity downward, towards the centre of the star, radiation pressure from the brilliant. continuous spectrum of the photosphere directed outward, and radiation pressure within the Lyman alpha line of hydrogen from the tenuous shell. This latter force is directed inward in the deeper regions of the atmospheric shell, and outward in the outermost regions. A small disturbance of the balance of these forces causes the entire structure to collapse, if gravity predominates, or to expand, if the outward components of radiation pressure predominate.

\section{USE OF SNOWFLAKE REPLICAS FOR STUDYING WINTER STORMS}

\section{BY VINCENT J. SCHAEFER}

Research Laboratory, General Electric Company, N.Y.

A METHOD was described last winter by me $e^{1,2}$ A for making permanent replicas of snowflakes, ice crystals and other forms of evanescent objects.

The technique, in brief, is to cover the frozen object with a cold dilute solution of an appropriate resin dissolved in a suitable solvent. After the solvent evaporates, a very thin continuous film reproduces in intimate detail all the surface configurations of the specimen. The substance of the original object is then removed by sublimation or by melting and evaporating, after which the resin shell, which optically appears identical to the original object, may be photographed and studied at leisure. A $1-2$ per cent solution of polyvinyl formal ${ }^{3}$ dissolved in ethylene dichloride (1-2-dichloro thane) reproduces excellent replicas of snowflakes and other forms of frozen moisture.

For collecting snowflakes a piece of black velvet stretched on a board is used to eatch the specimens. A small drop of the resin solution is placed on a glass slide with a tapered rod. 'The rod, which still retains a small amount of the resin solution, is then immediately brought into light contact with the selected specimen and the flake readily adheres to it by surface tension. The specimen leaves the rod when it is brought into contact with the drop of liquid on the slide. All equipment is kept outdoors in a sheltered place throughout the winter.

Since the method of making permanent replicas is so simple, it would seem that those interested in winter weather phenomena might secure specimens from various types of storms for detailed study of these fascinating frozen forms in their possible relation to later meteorological occurrences. To illustrate these possibilities, the thirty-six photomicrographs reproduced herewith were obtained in a thirty-minute fall of large snow crystals at Schenectady, New York, U.S., during 7.00-7.30 a.m., March 12, 1941. During this short period, 150 specimens were collected and of these the 36 photomicrographs reproduced represent a typical cross-section of the replicas obtained. In securing these specimens the collecting board was cleaned every few minutes to make sure that representative crystals were secured throughout the fall. The photomierographs were all made at the same magnification, so that the change in size as well as form can readily be seen in the photograph.

The climatic conditions when the specimens were collected showed a falling barometer at $29 \cdot 70$ in., a temperature of $26^{\circ} \mathrm{F}$. with a north-west wind blowing. As happens frequently in this section of the United States, the crystal fall of large symmetrical crystals occurred at the close of a storm which deposited a total of about ten inches of snow. The snow of the storm contained a large amount of water $(0.09 \mathrm{in}$. water per inch of snow) so that we

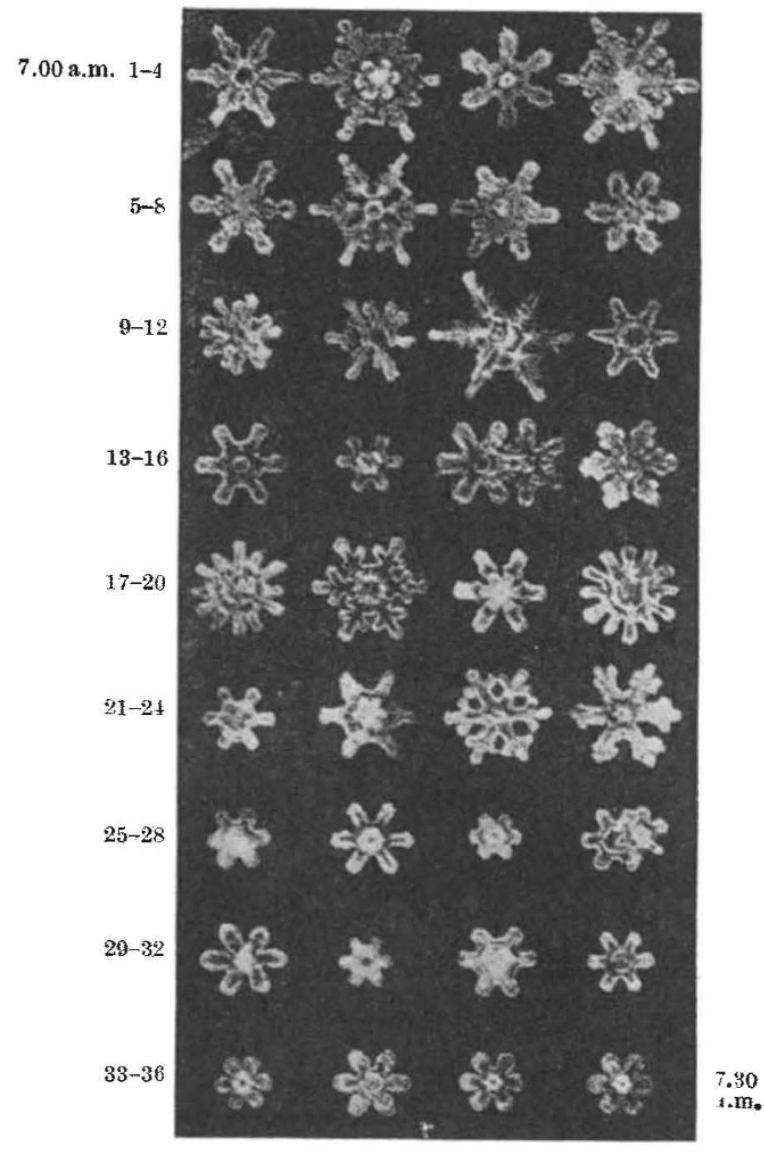

would term it a 'wet' snow. At 7.30, when I stopped collecting, the symmetrical crystals were replaced by the more common non-erystalline forms of assymetrical flakes which continued for several hours, after which the wind changed and the skies cleared. It will be noted that the crystals collected at the start of the fall had a considerable amount of secondary deposits which gradually disappeared as they decreased in size and changed in form.

Other forms of frozen precipitation such as sleet, graupel and ice crystals, terrestrial forms such as columnar and tabular frost, as well as breath patterns and crystals of low melting point such as benzene and acetic acid may all be prepared in replica form. by the method described.

1 Science, 98, 239 (1941).

Museum News, 19, No. 6, p. 11 (1941).

- Shawinigan Prod. Corp. Shawinigan Falls, Ontario, Canada. 